\title{
Raízes históricas das ideias que subsidiam as políticas de clustering
}

\author{
Historical roots of the ideas that subside clustering policies
}

ALEXANDRE RANDS BARROS*

RESUMO: Este artigo mostra as concepções básicas das ideias subjacentes que apoiam as políticas de agrupamento e explica suas origens e justificativas para desempenhar um papel importante no desenvolvimento econômico. Argumenta-se que, embora tenham sido promovidas enquanto as ideias liberais eram hegemônicas, os conceitos que dão suporte às políticas de agrupamento não se baseiam apenas nessa ideologia. Eles também buscam apoio em ideias que aceitam intervenções públicas na economia. Isso significa que uma das estratégias mais eficientes para promover o desenvolvimento econômico atualmente tem atitudes céticas em relação a vários preceitos liberais.

PALAVRAS-CHAVE: agrupamento, polos insdustriais, industrialização.

ABSTRACT: This paper shows the basic conceptions of the underlining ideas supporting clustering policies and explains their origins and justifications, for playing an important role on economic development. It is argued that, although they were fostered while liberal ideas were hegemonic, the concepts that give support to clustering policies are not based on this ideology only. They also seek support from ideas that accept public interventions on the economy. This means that one of the most efficient strategies to promote economic development nowadays has skeptical attitudes in relation to several liberal precepts.

KEYWORDS: clustering, industrial hubs, industrialization.

JEL Classification: E52, E53.

\section{INTRODUÇÃO}

O conceito de cluster está, a cada dia, tornando-se mais popular. A experiência bem-sucedida de políticas de clustering em todo o mundo, com grande concentração em países desenvolvidos, como Estados Unidos, Itália, Alemanha, entre outros, passou a chamar a atenção de instituições internacionais envolvidas na promoção do desenvolvimento em países pobres, tais como o Banco Mundial.

\footnotetext{
* Professor do Departamento de Economia da Universidade Federal de Pernambuco. E-mail: acbarros@ gmail.com; Orcid: 0000-0002-9851-4944.
} 
O empenho recente do Banco Mundial e da UNIDO em promover experiências de clusters no terceiro mundo, como é o caso do Nordeste brasileiro e da Guatemala, passou a chamar a atenção para os métodos e conceitos envolvidos. Além disso, a existência de experiências concretas bem-sucedidas no terceiro mundo, como são os exemplos de Chihuahua, no México, e o da Malásia, também criou a idéia de que esse tipo de política pode ser bem-sucedida nas regiões mais necessitadas do globo.

No Brasil essa idéia se popularizou a partir do projeto Iniciativa pelo Nordeste, que tem no Banco Mundial um de seus incentivadores e que também tem sido financiado pelos governos dos estados da Bahia, de Pernambuco e do Ceará. Além disso, a falha dos métodos tradicionais de planejamento no País e a falha da experiência recente de tentativa de desenvolvimento via forças de mercado fez com que houvesse muita receptividade à idéia de cluster.

Diante dos interesses despertados por essa idéia, este trabalho buscará discutir algumas idéias sobre a origem das hipóteses teóricas por trás das idéias de clustering. Ele está organizado como segue: a próxima seção aponta alguns conceitos básicos relevantes para a discussão de clustering e a terceira seção traz uma explanação dos objetivos de uma política de clustering. A quarta seção discute as origens históricas das idéias de clustering, e a seção cinco explicita a relação de vantagens competitivas e vantagens comparativas, conceitos que estão ligados à idéia de cluster. A seção seis, por sua vez, apresenta um confronto entre políticas de clustering e planejamento estratégico, que é tantas vezes confundido durante o processo de implementação das primeiras. A seção sete traz alguns comentários sobre a adoção de estratégias de clustering no Brasil e a seção oito resume as principais conclusões do trabalho.

\section{ALGUNS CONCEITOS BÁSICOS}

Antes de prosseguir, esta seção apresentará alguns conceitos básicos que são importantes para o leitor que até agora não se deparou com esse tema, pois ainda não faz dois anos que os conceitos relativos a cluster tornaram-se importantes no Brasil.

Cluster é um agrupamento de empresas que conta com algumas empresas líderes, geradoras de riqueza via comercialização de produtos e/ou serviços competitivos, e no qual também incluem-se aquelas empresas que as abastecem de insumos e serviços, além de todas as organizações que oferecem recursos humanos capacitados, tecnologia, recursos financeiros, infra-estrutura física e clima de negócios ${ }^{1}$. Um conceito alternativo pode ser visto nas palavras de Michael Porter:

\footnotetext{
${ }^{1}$ Este conceito foi apresentado por Maurício Romão que, na época, era o Coordenador do Comitê Executivo da Iniciativa pelo Nordeste.
} 
“Clusters são concentrações geográficas de empresas e instituições interconectadas numa área de atuação particular. Eles incluem um conjunto de empresas e outras entidades ligadas que são importantes para a competição. Eles incluem, por exemplo, fornecedores de insumos especializados, como componentes, máquinas, serviços e provedores de infra-estruturas especializadas. Clusters, freqüentemente, estendem-se na cadeia para incluir canais de comercialização e mesmo compradores, ou produtores de bens complementares, atingindo algumas vezes empresas relacionadas por qualificação da mão-de-obra, tecnologias, ou insumos comuns. Finalmente, muitos clusters incluem instituições governamentais e de outra natureza, tais como universidades, instituições de controle de qualidade, instituições de pesquisa e geração de idéias, especializadas em qualificação profissional, e associações patronais, que provêem treinamentos especializados, educação, informações, pesquisa, e suporte técnico.” (Porter, 1998a, pp. 78)

Esse conceito de Michael Porter mostra que um cluster inclui um espectro grande de empresas e instituições que se relacionam no processo de determinação da eficiência de um certo bem ou serviço que ele oferta para os agentes externos à sua cadeia produtiva. A figura 1 traz uma representação esquemática desses agentes. Vale salientar que quando nele se incluem consumidores, estes são de grande porte e participam com um percentual razoável da demanda de seus produtos finais. Por exemplo, no caso dos clusters de grãos, geralmente incluem-se as grandes tradings, que são responsáveis pela compra de boa parte de seus produtos finais.

Clustering é a política de promoção de clusters. Apesar de se reconhecer que há uma tendência para que os clusters se formem naturalmente, há ganhos na sua formação e integração que não são facilmente perceptíveis e apropriados pelos agentes que se incorporam a eles. Quando um novo agente se insere e se integra a um cluster, ele gera ganhos que são de fato apropriados por outros membros. Dessa forma, o seu estímulo a se integrar é menor do que o ganho para todo o cluster. Isso é verdadeiro não só para a introdução de um novo agente, mas também para a inserção de novas atividades e relações que antes não eram travadas dentro do cluster. Esse fato faz com que os sinais de mercado não sejam eficientes na formação e integração de clusters e, portanto, haja espaço para políticas ativas de formação e integração de clusters, que são denominadas "políticas de clustering".

Por exemplo, um comerciante especializado em fornecer um determinado insumo, que já seja membro de um determinado cluster, pode em algum momento tornar-se produtor dessa matéria-prima. Já sendo membro do cluster antes, ele apenas introduz uma nova atividade. Para os demais membros que compram essa matéria-prima, esta mudança de origem pode se tornar uma forma de ajustá-la a suas necessidades, melhorando sua eficiência. Esse ganho adicional, porém, será em sua maior parte apropriado pelos compradores da matéria-prima, não pelo seu fornecedor. Desta forma, o estímulo deste para desenvolver a produção da matéria- 
-prima é menor do que os ganhos que todo o cluster terá. Neste caso, essa introdução deve ser impulsionada por uma política de clustering.

Figura 1: Representação Esquemática da Estrutura de um Cluster

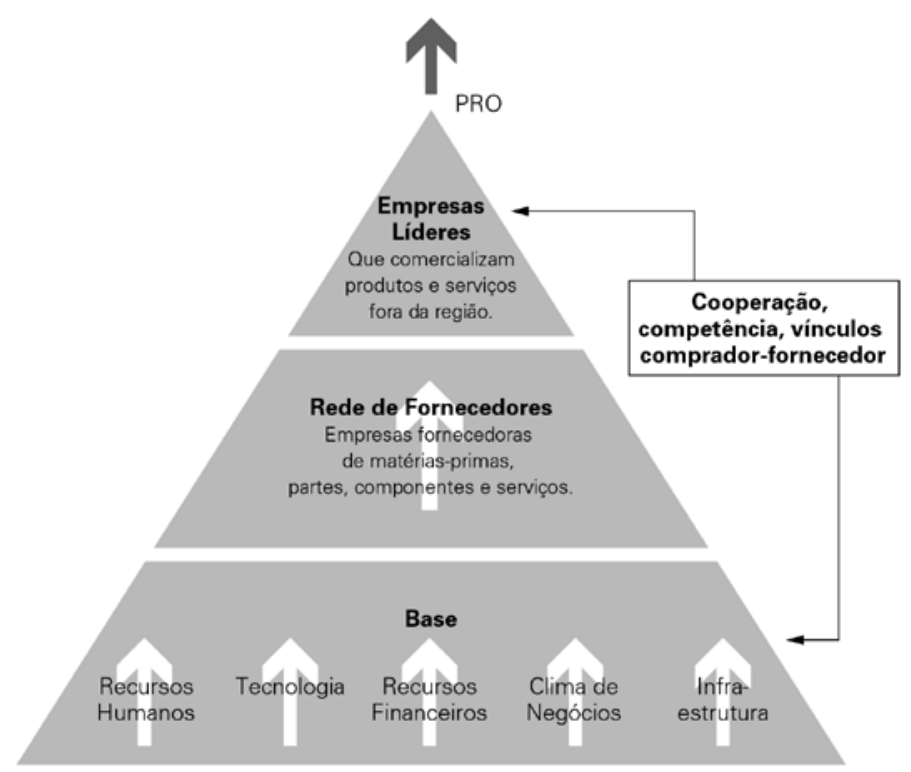

\section{O QUE AS POLÍTICAS DE CLUSTERING DEVEM FAZER}

As políticas de clustering têm como objetivo principal promover a eficiência dos clusters, com vistas a torná-los mais competitivos e, assim, possibilitar o seu crescimento. Para isso elas buscam:

- Viabilizar os investimentos em infra-estrutura econômica que possam ser úteisao desenvolvimento da competitividade do cluster e que sejam eficientes na alocação de recursos, sejam eles públicos ou privados.

- Viabilizar os investimentos em recursos humanos e tecnologia, com vistas asatisfazer as necessidades dos clusters e fomentar o aperfeiçoamento dos seus processos produtivos.

- Atrair novos empreendedores que possam integrar mais as cadeias produti-vas e com isso melhorar o fluxo interno de informações, além de reduzir os seus custos.

- Facilitar a prestação de serviços pelos agentes financeiros com vistas a con-tribuir na expansão dos clusters.

- Criar mecanismos que facilitem o fluxo de informações dentro do cluster, tanto entre seus próprios agentes como com o resto do mundo. 
Todas essas ações têm como motivação básica a busca da superação de falhas dos mercados na alocação dos recursos, ou acelerar sua ação para se atingir níveis de eficiência de forma mais rápida. Os métodos para se atingir esses fins são variados e dependem não só da própria estrutura da política de clustering, mas também das circunstâncias específicas do cluster e das relações entre seus agentes.

Os investimentos em infra-estruturas econômicas produzem externalidades e, portanto, a sua alocação de recursos não será eficiente se apenas sujeita aos ditames das forças de mercados. Neste caso particular, a política de clustering pode agir em dois sentidos. O primeiro é revelar as necessidades de infra-estrutura existentes que possam elevar a competitividade dos clusters. Obviamente elas têm de ser ordenadas, pois os recursos são sempre bem mais limitados do que as demandas por eles. O segundo é também no sentido de coordenar as demandas dos agentes envolvidos no cluster para as prioridades de investimentos do setor público. Em cada ambiente econômico há sempre um conjunto grande de agentes, sendo alguns deles ligados aos clusters mais importantes, mas muitos sem uma vinculação mais direta com eles. Nas decisões sociais sobre as prioridades de investimentos em infra-estrutura, esses agentes tendem a participar das revelações das preferências. Se os clusters não tiverem devidamente organizados e sob uma coordenação única, as demandas de seus indivíduos tendem a se espalhar pelos diversos projetos propostos, inclusive alguns que não são prioritários para os clusters. Por conseqüência, a existência desses outros indivíduos no mesmo espaço econômico pode fazer com que as prioridades definidas para os investimentos não sejam aquelas que seriam de maior interesse para o desenvolvimento dos clusters. Essa possibilidade e a falta de informações adequadas por causa das falhas nos sinais de mercado justificam a identificação e esforço para execução dos investimentos prioritários de infra-estrutura das políticas de clustering.

Os investimentos em recursos humanos e em tecnologia sofrem da mesma síndrome que aqueles em infra-estrutura. Eles geram externalidades positivas e, por tal, os agentes privados não alocam a quantidade socialmente ótima de recursos para sua produção. Também nestes casos, as políticas de clustering têm como objetivo apontar as necessidades existentes para a competitividade dos clusters, assim como coordenação dos agentes para gerar a demanda por esses investimentos.

Em ambos os casos, investimentos em infra-estruturas e em recursos humanos e tecnologia, também faz parte de uma política de clustering tentar promover a colaboração dos setores públicos e privados para viabilizar os investimentos necessários para incrementar a competitividade dos clusters, pois nos dois casos esta colaboração pode render bons resultados.

Muitas vezes os agentes privados que poderiam ter um papel importante na promoção da eficiência de um determinado cluster não definem investimentos na área por causa do risco de não se tornar fornecedor dessa matéria-prima, serviço ou bem intermediário para os compradores do cluster na escala necessária para viabilizar a sua nova unidade produtiva. Neste caso, uma política de clustering pode ajudar a garantir essa demanda mínima por coordenação dos agentes na demanda por esse bem ou serviço. Neste caso, eliminou-se uma falha de mercado 
associada à informação imperfeita, que pela política tornou-se suficientemente disponível para assegurar a credibilidade necessária nos resultados dos investimentos.

Uma política de clustering pode ajudar na disponibilidade de crédito tanto de curto como de longo prazo para os agentes envolvidos em um cluster. As dificuldades de crédito emergem por duas razões. Em primeiro lugar, a falta de credibilidade do banco ou outro agente financeiro de que a empresa pode honrar seus compromissos, o que depende de sua dificuldade de acreditar nas projeções positivas de rendimento da empresa. Em segundo lugar, o banco pode não ter confiança total de que o agente tomador incluirá o pagamento dos empréstimos como prioridade de gasto. Em terceiro lugar, o banco pode achar que o fluxo de caixa da empresa não assegurará a disponibilidade de liquidez necessária para honrar os compromissos financeiros assumidos dentro do horizonte temporal que seja adequado para o banco.

Em todos esses fatores que podem gerar restrições creditícias, há sempre um componente relacionado com as incertezas, que decorrem da existência de um universo incompleto de informações sobre as atividades do cluster e os seus agentes. Uma política de clustering pode operar exatamente nesse determinante de dificuldades de acesso a recursos financeiros. Ela pode gerar a colaboração necessária para que se passe a gerar um volume adequado de informações e que, dessa manei$\mathrm{ra}$, os recursos aplicados possam ser classificados como menos arriscados.

As políticas de clustering podem também integrar os agentes envolvidos para que possam aumentar a troca de informações entre eles, o que tende a estimular a busca de melhorias tecnológicas e posicionamentos no mercado, reduzindo também os custos associados à precaução nas transações intracluster, pois a maior interação entre os agentes facilita o conhecimento sobre as reais circunstâncias dos demais.

Além de assegurar o maior fluxo de informações entre os agentes que compõem o cluster, a política de clustering pode também promover a cooperação entre os agentes para que possam aumentar as informações sobre a realidade do cluster para os agentes externos, seja por meio de divulgação de seus produtos ou das oportunidades de negócios existentes. Além disso, ela pode também criar mecanismos de cooperação na obtenção de informações sobre os desenvolvimentos econômicos e técnicos das atividades do cluster, o que é crucial para a eficiência da tomada de decisão dos seus agentes.

\section{RAÍZES HISTÓRICAS DAS IDÉIAS DE CLUSTERING}

A idéia de clustering tem origem em várias das ideologias econômicas modernas, apesar de seus fundamentos não terem sido desenvolvidos pelos economistas. Essas raízes podem ser encontradas principalmente nas idéias liberais, que dominaram o mundo político desde o início da década de oitenta, com a eleição de Ronald Reagan e Margareth Thatcher, para presidente dos EUA e primeira ministra do Reino

Unido, respectivamente; mas que já ganharam hegemonia entre os economistas 
desde o início da década de setenta, sob a liderança de Milton Friedman. Entretanto, ela também se serviu de idéias nacionalistas associadas às ideologias protecionistas dos anos cinqüenta e sessenta. Além disso, elas também se utilizaram de conceitos desenvolvidos pela linha de pesquisa de Puttman ${ }^{2}$ que, já no início da década de oitenta, enfatizava o papel do associativismo para o desenvolvimento econômico, e dos ensinamentos dos países de crescimento acelerado desde 1950, tais como Coréia, Taiwan, Japão, Alemanha e Brasil.

\subsection{Fontes liberais}

Em suas origens, a justificativa das políticas de clustering basearam-se em aspectos específicos de cada um de seus fundamentos, não necessariamente incorporando todas as idéias centrais associadas a cada uma dessas fontes ideológicas. No caso específico das fontes liberais, vale destacar as seguintes idéias, que têm uma influência grande nas concepções por trás da filosofia e políticas de clustering:

As forças de mercado produzem os sistemas informacional e de auto-disciplina mais apropriados para promover o crescimento econômico. Em nível teórico essa idéia ganhou força com o teorema de que mesmo quando há imperfeições de mercado em que, por conseguinte, uma intervenção pública possa elevar o bem-estar social, ainda assim a disciplina gerada pelas forças de mercado podem ocasionar um resultado concreto mais eficiente, dado que evita comportamentos de rent seeking. ${ }^{3} \mathrm{Ou}$ seja, as forças de mercado têm um papel disciplinador crucial junto aos agentes econômicos; algo que não pode ser substituído por outros mecanismos de controle. Desse princípio a política de clustering herdou sua tendência de defender a necessidade de enfatizar o papel dos sinais de mercado para definir as prioridades de ação. Toda a ênfase em atuações coletivas deve ter como objetivo remover obstáculos ao desenvolvimento dos agentes privados, atuando sujeitos às forças de mercado.

O setor público é ineficiente na alocação de recursos e, portanto, tem pouco poder para elevar o bem-estar social acima do que as próprias forças de mercado são capazes de fazer. Essa tese enfatiza um aspecto particular da apresentada anteriormente. Ela destaca a tendência do setor público de promover a busca e sedimentação de interesses particulares que vão de encontro ao interesse coletivo. A política de clustering incorporou a idéia de que o setor público deve perder seu domínio sobre a definição das ações de promoção do desenvolvimento e deve ter como sua estratégia de atuação a submissão a prioridades que sejam definidas coletivamente pelos agentes envolvidos nos clusters. Ou seja, ele deve passar a ter um papel de ator coadjuvante, deixando de ser o personagem central da política de desenvolvimento.

\footnotetext{
${ }^{2}$ Ver, por exemplo, Puttman (1992).

${ }^{3}$ A importância do rent seeking behaviour como forma de gerar ineficiência e o papel do mercado para controlar o efeito perverso desse comportamento foi enfatizado por Krueger (1974).
} 
A defesa do interesse individual é o mecanismo mais eficiente para se atingir o interesse coletivo. Essa é a idéia da 'mão invisível' de Adam Smith, que defende que o comportamento de busca de maximizar seus lucros levam os indivíduos a gerarem eficiência na alocação de recursos, maximizando o produto e bem-estar que pode-se obter a partir de uma determinada quantidade de recursos. Diante desta concepção, a definição da alocação de recursos na sociedade deve ser deixada o máximo possível sob a responsabilidade dos agentes individuais. Isso significa que os agentes individuais que são responsáveis pela alocação de recursos na sociedade - os empresários - devem também ter papel importante na alocação de recursos públicos, pois o seu viés para buscar promover seus próprios interesses produzirá como resultado a eficiência na elevação do bem-estar coletivo. Ressalta-se, entretanto, que isso só será verdadeiro caso eles participem da decisão da alocação dos serviços públicos coletivamente; de outra forma o rent seeking behaviour pode prevalecer.

Apesar de absorver as principais idéias do pensamento liberal, a política de clustering advoga algumas diferenças importantes em relação ao que os adeptos do liberalismo defendem. Três diferenças destacam-se. Em primeiro lugar vale salientar aquela que diz respeito à intervenção em comércio internacional. Enquanto os liberais defendem que o governo não deve intervir nas relações comerciais internacionais, deixando as forças de mercado atuarem, os adeptos da política de clustering defendem que os governos podem contribuir para o bom desempenho comercial dos seus clusters via coordenação de cooperações comerciais entre seus agentes, sejam elas para aumentar o volume e a barganha nas relações comerciais ou para reduzir custos de marketing e informações. Vale salientar, contudo, que provavelmente poucos liberais discordariam de tais intervenções. Entretanto, a existência de um papel importante para elas no ganho de competitividade não é enfatizado entre os liberais, pela sua dificuldade de ressaltar o papel das falhas de mercado na definição de políticas.

A segunda diferença de destaque diz respeito ao papel do planejamento. Enquanto os liberais advogam que o planejamento público é irrelevante e deve ser evitado, pois serve apenas como instrumento de pressão de grupos sociais específicos, os defensores de uma política de clustering vislumbram o planejamento como necessário, mas dentro de uma concepção oposta aos padrões históricos das últimas três décadas. Em vez de concentrar sua atenção em tentar direcionar as atividades do setor privado, o planejamento público deveria buscar, conjuntamente com os diversos agentes dos principais clusters, identificar os obstáculos ao desenvolvimento de sua competitividade e concentrar sua atenção na definição de estratégia e plano de ação que possam superar esses obstáculos, por meio de uma participação conjunta de agentes públicos e privados.

A terceira diferença de destaque quanto às políticas sugeridas é a ênfase em investimentos públicos como forma de promover o desenvolvimento. Enquanto os liberais advogam a sua restrição a um mínimo muitas vezes circunscrito a poucas áreas em que as falhas de mercado são óbvias, como investimentos em educação, para citar o exemplo de Adam Smith, os adeptos da metodologia de clustering 
sugerem que o governo deve ter métodos participativos para definir esses investimentos, sem contudo, ser tímido na sua execução, desde que sejam necessários para promover a competitividade dos clusters. Ou seja, também quanto aos investimentos públicos, a metodologia de clustering tem uma postura mais pragmática do que preconizada pela ideologia liberal e é mais tolerante quanto ao papel do governo na economia.

\subsection{Fontes nacionalistas}

Apesar de sua ênfase na necessidade de se respeitar os sinais do mercado, as políticas de clustering também se utilizam de algumas idéias cujas origens e evidência podem ser encontradas nas doutrinas nacionalistas. Esse fato pode ser vislumbrado a partir da própria valorização da concentração espacial como uma fonte importante de ganho de competitividade ${ }^{4}$. Essas idéias têm seus fundamentos nas seguintes proposições, que desempenharam papel tão importante na definição das doutrinas nacionalistas, tal qual a que ficou conhecida na América Latina como o Pensamento Econômico da CEPAL:

Existe um bem social que emerge das atuações individuais e que consiste em externalidades para os agentes individuais. Os agentes individuais, ao desenvolverem seus próprios negócios, geram uma série de externalidades que promovem a produtividade de outros agentes. Um exemplo simples pode ser obtido a partir de um simples ato de demanda de um certo insumo, cuja produção é realizada em um espaço econômico longínquo. Caso esse produtor mantenha-se operando isoladamente, ele terá de incorrer em altos custos de transporte e comunicação para obter o insumo, além de ter de pagar um preço mais elevado pelo risco que o fornecedor tem em operar com ele. Este último custo adicional decorre do fato de esse comprador não ser uma pessoa cuja situação da empresa seja fácil de acompanhar e, portanto, sempre poderá estar prestes a ter problemas de insolvência, sem que sejam previamente detectados pelo fornecedor ${ }^{5}$. Tudo isso leva a que este último pague custos elevados, que podem ser reduzidos quando os agentes estão próximos e atuam no mesmo meio social. Esse tipo de externalidade está na raiz daquilo que os economistas chamam de efeito aglomeração e que tem sido utilizado como uma das possíveis justificativas para os resultados empíricos que indicam que há um crescimento da produtividade quando há expansão da renda ${ }^{6}$.

A promoção do bem coletivo gera benefícios para os agentes individuais. Políticas que venham a promover o bem-estar coletivo, tais como investimentos em infraestrutura social ou em educação, também beneficiam as empresas privadas,

\footnotetext{
${ }^{4}$ Ver, por exemplo, Porter (1998a e 1998b).

${ }^{5}$ Porter (1998a, pp. 81-83) lista uma série de relações que podem justificar a redução de custos por decorrência da proximidade física.

${ }^{6}$ Para uma discussão recente deste aparente paradoxo que contraria a hipótese dos rendimentos marginais decrescentes, ver Basu e Fernald (1997).
} 
pois estas servem-se de alguns desses serviços e poderão contar com trabalhadores mais felizes e, dessa maneira, mais eficientes, pelo chamado 'Efeito Myrdal'7. Entretanto, o impacto na produtividade dos diversos agentes sociais, decorrente de políticas de promoção do bem-estar coletivo, pode ser bastante diferenciado. Desta forma, os agentes individuais integrados nos clusters mais competitivos de uma determinada região devem ser ouvidos no processo de definição dessas políticas para que os recursos sociais sejam mais eficientemente utilizados.

Os investimentos em infra-estrutura podem gerar ganhos sociais acima do que pode ser apropriado por agentes individuais. Os defensores de políticas de clustering também têm sempre presente o fato de que o mercado, apesar de ser o melhor instrumento disponível para a alocação de recursos, também tem falhas, que demandam políticas públicas para que a eficiência econômica seja mais elevada. As externalidades associadas aos investimentos em infra-estrutura são um exemplo. Algumas vezes a capacidade de apropriação de renda a partir dos investimentos em infra-estruturas pode ser aquém do que é efetivamente gerado para a sociedade. Nesses casos, a intervenção coletiva, dentro de uma política colaborativa entre agentes públicos e privados pode trazer a alocação de recursos para o ótimo social. O exemplo da colaboração entre os produtores de grãos de Barreiras, na Bahia, e o governo baiano, para melhorar a qualidade das estradas locais no oeste baiano consiste em uma dessas colaborações que é tão apregoada pela política de cluster $^{8}$.

As externalidades entre as diversas atividades econômicas consistem em motor importante do crescimento econômico. Assim como reconhecido por Shleifer (1991) e tão propagado por toda a Nova Teoria do Crescimento ${ }^{9}$, mas que já era enfatizado pelos estruturalistas latino-americanos ${ }^{10}$, a externalidade é vista como um importante motor do crescimento econômico. Essas externalidades, contudo, não se limitam a atividades específicas, como ocorre na Nova Teoria do Crescimento Econômico. Elas também emergem nas atividades mais banais, como é o caso, por exemplo, de uma simples troca de mercadorias. Além da mudança de mãos do dinheiro e do bem ou serviço, essa transação gera também uma informação, que serve aos seus participantes e aos demais agentes que têm acesso a ela para ajustarem sua visão sobre os agentes envolvidos, além das próprias tendências do mercado. Por exemplo, se um agente qualquer vende um carregamento de açúcar para um trader que o levará à China, ele, automaticamente, gera informações relevantes para todos os agentes do mercado. Entre as possivelmente relevantes, vale salientar o fato de a China estar entrando naquele período no mercado, a escassez de açúcar na Tailândia, na Indonésia e em outros exportadores da região etc. Todas essas informações, que consistem em externalidades, podem ser muito importantes para

\footnotetext{
${ }^{7}$ Ver Barros (1994).

${ }^{8}$ O Governo do Estado da Bahia entrou com os equipamentos, e os produtores com a mão-de-obra e os insumos para a melhoria das estradas da região produtora de soja de Barreiras.

${ }^{9}$ Ver, por exemplo, Romer (1994).

${ }^{10}$ Ver Barros (1993).
} 
os demais agentes, que podem estar, por exemplo, prestes a fixar seus preços na bolsa de mercadorias. Esse tipo de externalidade é que justifica, por exemplo, a alteração de preços nas bolsas de valores e mercadorias, quando os agentes que operam no mercado real, não apenas na bolsa, entram no mercado comprando ou vendendo. Esse tipo de informação gerada nas diversas transações e tomadas de posição (decisão de investir, por exemplo) é que faz com que os clusters com maior proximidade geográfica e interação entre seus agentes tendam a ser mais eficientes. Além disso, um dos ingredientes básicos de uma política de clustering é elevar a integração entre os diversos agentes que compõem o cluster.

Todas essas idéias também eram comuns aos teóricos nacionalistas, que por essas crenças passavam a enfatizar a importância da produção interna ao espaço nacional e a maior relação entre os agentes locais. As externalidades deveriam ser promovidas pelo setor público e as falhas de mercado suplantadas por sua iniciativa em assegurar os serviços cujos mercados seriam ineficientes em alocar recursos para eles. Com isso, o poder econômico nacional e o desenvolvimento seriam mais facilmente atingidos.

Vale lembrar, antes de encerrar esta seção, que há duas discordâncias básicas entre as políticas de clustering e as velhas receitas desenvolvimentistas dos nacionalistas. Estas decorrem da diferença de abordagem quanto ao papel das forças de mercado na alocação de recursos. São elas:

Visão quanto ao papel do planejamento. O reconhecimento da existência de falhas do mercado na alocação de recursos levou os nacionalistas a enfatizarem o papel do planejamento público a partir de informações colhidas pelos órgãos planejadores. Ou seja, o planejamento defendido pelos nacionalistas tinha uma natureza tecnocrata e baseava-se numa ideologia de que os técnicos poderiam ter informações melhores para os agentes privados do que as geradas pelo funcionamento dos mercados. Para os adeptos da política de clustering, os agentes econômicos são os mais aptos a apontarem os reais obstáculos ao desenvolvimento da competitividade de determinado cluster. Por tal, eles preconizam a troca do planejamento dentro de sua concepção tradicional por uma política de mobilização dos agentes envolvidos em um determinado cluster, para identificar esses obstáculos e implementar estratégias para sua superação, que tenham a participação dos diversos agentes envolvidos. O setor público neste tipo de planejamento participativo e desburocratizado tem apenas o papel de um coadjuvante em todo processo, deixando de ser o ator principal e que determina as prioridades.

Visão quanto ao protecionismo. Para os nacionalistas, a proteção seria um instrumento de geração de escala de produção e promoção de competitividade de alguns setores, via learning by doing. Desta forma, eles defendem a sua utilização como política corriqueira de desenvolvimento econômico. Para os adeptos da política de clustering, a visão seria completamente diferente. Como eles acham que (i) a competitividade deve ser obtida via integração entre os agentes, (ii) o rent seeking behaviour tende a ser importante, (iii) os sinais do mercado são os melhores instrumentos na alocação dos recursos na economia, eles advogam que a proteção não 
é uma boa política de desenvolvimento. Ela tende a promover a ineficiência e acomodação dos agentes.

Essas diferenças fazem com que, apesar de preconizarem algumas das idéias dos nacionalistas, os adeptos das políticas de clustering defendam práticas de políticas públicas bem diferentes. As suas políticas estão mais próximas das idéias liberais, apesar de também terem divergências importantes em relação às recomendações destes, como visto na subseção anterior.

\subsection{O papel do associativismo no desenvolvimento econômico}

Um dos pilares do enfoque de clusters na análise econômica é a visão de que as regiões que tiveram maior cultura associativa se desenvolveram mais rapidamente. Esses estudos, tendo como um de seus líderes o cientista político Robert Puttman, mostraram que a maior propensão à associação de uma determinada população leva a um desenvolvimento de longo prazo mais acelerado. O seu estudo principal sobre este assunto analisou o exemplo da Itália, onde as disparidades regionais são muito sérias e a origem de cidades-estado levou a diferenças culturais bastante sensíveis em um espaço que viveu sua história recente sob as mesmas regras institucionais. Utilizando-se de dados existentes sobre as associações não-governamentais nas diversas regiões daquele país, ele mostrou que as que detinham um maior número de associações tornaram-se mais desenvolvidas.

A justificativa por trás dessa correlação entre grau de associativismo e desenvolvimento econômico é que um volume grande de informações flui nas relações sociais, muitas vezes com um nível elevado de credibilidade, o que faz com que elas sejam informações altamente eficientes. Nas relações sociais também se geram teias de relações pessoais que fomentam a credibilidade entre os agentes. Essas teias são muito importantes para reduzir os custos de transação na economia e, por conseguinte, contribuem para acelerar o desenvolvimento econômico.

O ser humano tende a ter níveis variados de interação social. Entretanto, se considerarmos as diversas dimensões da vida humana pode-se iniciar a compreensão desse fenômeno partindo-se do pressuposto de que os indivíduos despendem, em média, um mesmo percentual de seu tempo em interação direta com outras pessoas. Obviamente isso não é verdade. Porém, consiste em uma boa aproximação para efeito de raciocínio. Os indivíduos dividem esse tempo de interação com outros semelhantes entre várias atividades, sendo as principais trabalho e lazer.

Suponha-se adicionalmente que a interação social no tempo de trabalho é semelhante nas diversas sociedades. Essa também é uma suposição irrealista, pois essa interação depende das tecnologias de produção e processo, que variam entre as sociedades. Entretanto, para espaços mais agregados, que seriam conjuntos de cidades, essa suposição de que o tempo de interação, e até mesmo os tipos de agentes com quem cada indivíduo interage no trabalho, são semelhantes, não é muito distorciva em relação à realidade. A utilização dessa suposição poderá contribuir para que se perceba com maior clareza os determinantes fundamentais da relação entre associativismo e desenvolvimento econômico e, dessa maneira, ela é útil aqui. 
Com esta suposição, devese voltar a atenção às diferenças existentes na alocação do tempo de lazer.

As interações com os semelhantes nos momentos de lazer são mais diversificadas. Entre as diversas opções, cabe destacar o tempo despendido: (i) com familiares; (ii) com amigos relacionados à escola, esportes, hobbie ou festas; (iii) com amigos relacionados à vida profissional; e (iv) com estranhos em alguns tipos de festas e até mesmo em atividades esportivas.

Quando um determinado país ou região tem cultura associativa mais elevada, as interações com amigos relacionados à vida profissional assumem um maior destaque. Nessas relações, a troca de informações sobre aspectos que possam contribuir com o desempenho profissional dos indivíduos é muito maior do que nas demais relações. Conseqüentemente, quanto maior for o papel dessas relações entre indivíduos cujo interesse comum é profissional, maior será o fluxo de informações que reduzem os custos de transação da economia. Obviamente, o tempo gasto nesse tipo de interação será maior quanto maior a cultura associativa profissional. Os outros tipos de interação acima mencionados tendem a gerar menos informações economicamente relevantes, o que reduz o seu papel na promoção da queda nos custos de transação.

Vale salientar, contudo, que esses outros determinantes da interação entre os indivíduos também geram conhecimentos sobre o caráter e índole dos demais membros da sociedade. Isso faz com que interações que deles se originem também contribuam para a redução do custo de transação, pois há uma redução na demanda por instrumentos de proteção contra riscos nas relações comerciais advindas destes indivíduos que têm conhecimento sobre o caráter dos outros. Ou seja, as interações sociais tendem a reduzir os custos de transação e a promover o desenvolvimento, mesmo quando os seus determinantes não são profissionais. Entretanto, quanto maior a probabilidade de dois indivíduos que se relacionam socialmente interagirem também profissionalmente, maior será a queda dos custos de transação advindas da redução da demanda por segurança nas transações comerciais.

Essa idéia é fortemente utilizada pela concepção de clustering. Os seus defensores argumentam que o aumento da complexidade das cadeias produtivas em um mesmo espaço físico tende a reduzir os custos de transação entre os diversos agentes, por causa dos dois fatores acima mencionados: (i) maior interação social entre potenciais parceiros comerciais, o que reduz a demanda por segurança nas transações; (ii) maior fluxo de informações relevantes para as atividades econômicas dos agentes, a partir das suas interações sociais, o que reduz os custos de busca na definição de relações comerciais.

\subsection{Exemplos dos milagres econômicos}

Desde a Segunda Guerra Mundial, alguns países tiveram um excelente desempenho econômico. Entre eles cabe destacar Japão, Alemanha, Coréia do Sul, Taiwan, Singapura, Hong Kong e Brasil (ver tabela 1). A análise da experiência desses países 
serviu para que se obtivessem algumas conclusões importantes, mesmo que estas não fossem totalmente isentas de controvérsias.

Todos esses países contaram com políticas ativas de desenvolvimento, que não se limitaram apenas a regular os mercados e deixar os agentes privados agirem de acordo com seus incentivos individuais. Ou seja, eles não se constituíram em exemplos de sucesso do modelo liberal, apesar de haver algumas sugestões afirmativas nesse sentido ${ }^{11}$. Por outro lado, as intervenções do setor público adotadas nesses países também não foram exemplos de políticas públicas cujo princípio motor foi o desprezo pelas sinalizações de mercado $^{12}$, com uma possível exceção do caso brasileiro, onde se induziu a grandes distorções dos preços relativos internos quando comparados às relações de preços existentes no mercado internacional.

Tabela 1: Média anual da taxa de crescimento do PIB real per capita de países selecionados, 1960-1994 (em \%)

\begin{tabular}{llll}
\multicolumn{1}{c}{ País } & Taxa & \multicolumn{1}{c}{ País } & Taxa \\
\hline Japão & 4,9 & Taiwan & - \\
Alemanha* & 4,3 & Brasil** $^{*}$ & 5,5 \\
Hong Kong & 5,9 & Singapura & 6,4 \\
Coréia do Sul & 7,0 & Mundo*** $^{*}$ & 1,49 \\
\hline
\end{tabular}

Fontes: PNUD, Relatório do Desenvolvimento Humano 1997, Lisboa: Trinova Editora, 1997, para Japão, Coréia do Sul e Mundo. IBGE para dados do Brasil e Maddison (1991) para dados da Alemanha. Notas: * Dados para 1950-1980. ** Dados para 1965-1980. *** Dados para 1965-1993.

Ou seja, em todos esses países os governos tiveram políticas ativas de promoção do crescimento econômico. Contudo, com exceção do caso brasileiro, essas políticas não foram determinadas a partir de planejamento público restrito a pressões de poucos grupos de interesse. Eles tinham em mente uma preocupação com o bem-estar coletivo e respeitavam as sinalizações dadas pelos mercados. Os governos não desprezaram as demandas microeconômicas, mas não se tornaram vassalos de poucos grupos econômicos. As decisões de política eram tomadas quando se encontrava pontos de interesse comuns dos clusters econômicos importantes. Em troca de tais políticas, cobrava-se desses clusters competitividade internacional e excelência nas suas áreas ${ }^{13}$. Diante de tal filosofia, passou-se a definir investimentos e ações que se tornavam de co-responsabilidade dos setores público e privado.

Por exemplo, enquanto o governo japonês se empenhava em desenvolver todo um programa de educação e qualificação da mão-de-obra, as empresas se responsabilizavam em não deixar essa mão-de-obra ociosa, nem em criar políticas de

\footnotetext{
${ }^{11}$ Ver, por exemplo, o trabalho clássico de Balassa (1982) em relação a Taiwan e Coréia.

12 Ver Krueger (1996) e Stiglitz (1992).

${ }^{13}$ Ver, por exemplo, Lall (1992).
} 
cargos e salários que viessem a desestimulá-la. Essa política era vista como um compromisso das empresas com toda a sociedade.

Outros exemplos podem ser encontrados no caso da Coréia do Sul, que definia novos setores que passavam a ser prioritários, como, por exemplo, o automobilístico ou de construção naval, e definiam toda uma política para assegurar os serviços públicos e demais intervenções necessárias para torná-lo eficiente. Em contrapartida, as empresas que se engajavam naquela atividade comprometiam-se em se tornar competitivas e capazes de exportar para o mercado internacional. As políticas públicas cobriam todas as áreas em que havia falhas de mercado, tais como qualificação da mão-de-obra, pesquisa e desenvolvimento tecnológico, infra-estrutura pública, etc. Quando os benefícios desses serviços eram muito localizados em empresas ou grupos de empresas, elas também se comprometiam em participar do esforço coletivo. As metas de competitividade e eficiência internacional, contudo, não eram abandonadas e eram sempre fiscalizadas pelo setor público.

Esses exemplos de relações cooperativas entre ações do setor público e privado podem se multiplicar nesses países de alto nível de crescimento econômico no pós-guerra e serviram de base para as seguintes lições:

Os mercados têm falhas e, por isso, não devem ser os únicos determinantes da alocação de recursos internos numa economia. Esta lição tem suas origens teóricas nas interpretações estruturalistas do desenvolvimento e obtiveram suporte empírico dos exemplos de sucesso desses países.

Apesar de suas falhas, os mercados são os melhores sinalizadores e disciplinadores existentes para a alocação de recursos. Desta forma, quando eles falham, deve-se buscar estabelecer políticas que recomponham sua característica disciplinadora e distorçam o mínimo possível os seus sinais de preços. As políticas seguidas pelos países de rápido desenvolvimento mencionados acima, com exceção do Brasil, também tiveram essas características. Políticas de proteção tarifária, por exemplo, devem ter vida curta e ser adotadas de forma decrescente com períodos de redução pré-definidos.

O setor público tem de ter uma política cooperativa em relação ao setor privado, não o tratando como saqueador ou inimigo do bem coletivo. Quando as políticas públicas são necessárias, os governos devem adotá-las em conformidade com as demandas e necessidades do setor privado, servindo de parceiro deste e buscando promover sua eficiência. Esse setor privado, contudo, deve ser constituído de clusters amplos, não apenas pequenos grupos privilegiados específicos, que possam se tornar rent seekers. O governo não pode se tornar refém de pequenos grupos que venham a se beneficiar das benesses públicas em detrimento do interesse coletivo. Esta também foi uma prática comum nos países de rápido desenvolvimento já mencionados, também neste caso com a exceção do Brasil em vários exemplos. 


\section{VANTAGENS COMPETITIVAS VERSUS VANTAGENS COMPARATIVAS}

A idéia de vantagens competitivas tornou-se um dos conceitos mais ligados àpolítica de clustering. Ela é levantada em oposição à idéia de especialização definida a partir das vantagens comparativas, tal como sempre apregoado pela Teoria Neoclássica Tradicional. A valorização dessa idéia deu-se a partir da crítica freqüentemente apresentada pelos defensores da política de clustering em relação à idéia de vantagem comparativa. Segundo eles, não seria mais a dotação de fatores de produção que definiria a competitividade de uma região, mais a existência de clusters bem integrados e com boa infra-estrutura física, disponibilidade de recursos humanos e ambiente institucional, pois esses são os principais determinantes da eficiência na produção de uma determinada economia.

O que esses autores esquecem é que a Teoria das Vantagens Comparativas, tal qual apresentada inicialmente por Ricardo (1817), não se baseava na disponibilidade relativa de fatores de produção. Mesmo as versões mais sofisticadas dessa teoria hoje, dentro de uma estrutura de argumentação Neoclássica, em que se salienta o papel da disponibilidade de fatores de produção, não teria a noção estática de vantagem comparativa momentânea como único fator determinante de especialização e, assim, poderia comportar as supostas falhas da teoria que os seus críticos apresentam. O que de fato a noção de vantagem competitiva adiciona a essa visão mais ampla de vantagens comparativas é que ela enfatiza a necessidade de inclusão de ganhos associados às externalidades positivas como um determinante importante das vantagens comparativas. Obviamente, esta é uma mudança lógica na hipótese Ricardiana, desde que se identifique sua existência e reconheça-se sua relevância na definição de competitividade relativa.

Ou seja, a idéia de vantagem competitiva enfatiza a existência desses fatores associados a externalidades na definição das vantagens comparativas, não consistindo, contudo, numa negação desta. Quando se tenta colocar este conceito em oposição à Teoria das Vantagens Comparativas, apenas tenta-se apresentar um discurso com apelo político e comete-se um erro teórico ingênuo.

\section{PLANEJAMENTO ESTRATÉGICO VERSUS CLUSTERING}

Uma das formas de se desenvolver uma política de clustering demanda a mobilização dos agentes para identificar os obstáculos à sua maior eficiência. Esse processo é semelhante à maioria dos processos de elaboração de planejamento estratégico. Entretanto, a mobilização dentro de uma política de clustering tem dois papéis. O primeiro é identificar pontos de estrangulamento da produção que possam ser superados por ações conjuntas dos membros do cluster. O segundo, dentro da lógica de funcionamento dos clusters, busca elevar a integração dos seus membros. Esse segundo objetivo visa elevar o fluxo de informações entre os agentes, de forma que todos ganhem em eficiência, dentro da lógica já discutida em seções anteriores.

Esse processo de mobilização difere do seu similar na elaboração de um pla- 
nejamento estratégico porque tende a ser mais específico, já que toda a mobilização e identificação dos estrangulamentos são voltados para ações concretas dos agentes envolvidos que possam resultar em mudanças palpáveis. No planejamento estratégico os objetivos, estratégias, projetos e até mesmo ações propostas tendem a se estabelecer em um nível mais genérico, já que não estão ligadas a ações concretas que devem ser implementadas.

Em compensação, as ações propostas dentro de um planejamento estratégico tendem a servir de orientação para os executores do planejamento por muito mais tempo, pois seu não compromisso com ações imediatas permite que seus elaboradores possam ter uma preocupação temporal mais ampla. Como numa política de clustering uma das grandes preocupações é a integração dos agentes entre si, sua preocupação com ações que unam os agentes em torno de idéias que possam apresentar resultados palpáveis dentro de um horizonte de tempo mais curto é maior.

\section{POTENCIAL DE RESULTADOS NO CASO DO NORDESTE DO BRASIL}

A política de clustering no Brasil é nova, apesar de existir no país um dos exemplos internacionais de maior sucesso, de acordo com os textos sobre o assunto. $\mathrm{O}$ caso de Vale dos Sinos, no sul do Brasil, é tido como um exemplo em que a busca de cooperação entre agentes assegurou o sucesso na produção de sapatos, o que fez com que a região levasse o Brasil a se tornar um dos maiores exportadores de sapatos do mundo ${ }^{14}$. Não houve, contudo, nesse exemplo, uma política explícita de promoção do desenvolvimento do cluster, a partir de trabalho contratado com esse fim específico.

No caso do Nordeste, está se desenvolvendo um trabalho com apoio de consultoria para o fim de promover a integração de clusters escolhidos na região, que são: fruticultura, turismo, produção de grãos e informática. O trabalho da consultoria se estende a toda a área do Nordeste, mas tem se concentrado, pelo que se pode deduzir da própria lógica da política, naquelas áreas com real vocação competitiva nesses segmentos. A tabela 2 traz maiores detalhes sobre os clusters em que o trabalho está se desenvolvendo, por segmento de atividade.

Tabela 2: Clusters que estão sendo trabalhados por política de clustering da Iniciativa pelo Nordeste

\begin{tabular}{lccc}
\hline \multicolumn{1}{c}{ Fruticultura irrigada } & Grãos & Turismo & Informática \\
\hline Pertrolina-Juazeiro - PE/BA & Barreiras - BA & Porto Seguro - BA & Ilhéus - BA \\
Açu-Jaguaribe - RN/CE & Salvador - BA & Salvador - BA \\
Teixeira de Freitas - BA & Recife - PE & Recife - PE \\
& & Fortaleza - CE & Fortaleza - CE \\
\hline
\end{tabular}

Fonte: Datamétrica.

\footnotetext{
14 Para ver uma discussão sobre os desenvolvimentos do cluster de sapatos no Vale dos Sinos, ver Schmitz, 1995.
} 
Os trabalhos desenvolvidos até então têm apontado em direções variadas no que diz respeito aos resultados a serem alcançados. Alguns dos clusters que estão sendo trabalhados não têm demonstrado maior integração dos agentes que o compõem, apenas havendo utilização da Iniciativa pelo Nordeste como um instrumento de obter regalias do setor público, já que há um grande empenho desta, tanto em nível federal como estadual, para obter resultados. Nesses casos a mobilização dos agentes privados efetivamente não tem levado a um patamar de organização setorial superior. Após o fim dos trabalhos da consultoria dever-se-á voltar a estágios anteriores de mobilização, havendo pouco impacto efetivo no fluxo de informações e cooperação entre os agentes locais. Entretanto, vale salientar que esses casos ainda estão sob ação da consultoria, que, detendo conhecimento da situação, tentará reverter essa tendência, nos meses que ainda restam para o desenvolvimento dos trabalhos.

Em alguns casos, entretanto, a mobilização tem sido efetiva e tem contribuído para mudar a visão que os agentes privados têm das políticas públicas. Eles têm percebido que podem reverter essas velhas práticas do Brasil, em que a influência política clientelista ou os interesses de pequenos grupos empresariais são os principais determinantes de sua natureza e intensidade.

No setor público também se tem conseguido atingir grandes resultados. Vários segmentos do funcionalismo têm assimilado a ideologia de que os interesses dos setores econômicos competitivos nas prioridades coletivas são importantes para o desenvolvimento da região. Até recentemente, as lideranças do setor público oscilavam suas definições de políticas entre as prioridades definidas a partir dos interesses de grupos de apoio político ou aquelas que emergiam das necessidades dos que mais precisam de assistência social. Desta forma, as prioridades dos setores mais competitivos da região tendiam a correr à margem das prioridades das autoridades públicas. Essa mudança ideológica certamente deverá produzir resultados importantes para o desenvolvimento do Nordeste.

A política de clustering até então adotada, contudo, tem tido dificuldade de fomentar um espírito cívico mais forte entre os empresários privados, fazendo com que a sua colaboração na promoção do bem coletivo ainda seja limitada. Esse talvez seja seu grande desafio, pois esse espírito cívico do empresariado é um dos principais motores do desenvolvimento em clusters mais maduros $^{15}$.

\section{CONCLUSÕES}

Este trabalho teve como objetivo principal esclarecer alguns conceitos sobre clusters e discutir as origens das idéias que permeiam as políticas para sua promoção. A partir das discussões apresentadas pôde-se perceber que a política de clus-

\footnotetext{
${ }^{15}$ Para uma discussão do papel do espírito cívico dos empresários no desenvolvimento das regiões que aglomeram os clusters, ver Henton, Melville e Walesh (1997).
} 
tering incorpora vários dos desenvolvimentos recentes da teoria econômica como, por exemplo, o reconhecimento de que os mercados constituem-se excelentes sinalizadores para a alocação de recursos.

Entretanto, a ideologia por trás dessa política foi mais além e reconheceu que as externalidades existem e têm um papel importante na economia. Esse reconhecimento, contudo, não levou à posição radical de tentar suplementar os mercados pelo planejamento baseado em informações técnicas apenas. Ao contrário, ele tentou trazer a lógica de funcionamento dos mercados, que é a crença na mão invisível, para o planejamento daquelas atividades em que há falhas de mercado.

Essas idéias sobre clustering têm evoluído no Nordeste desde o início da Iniciativa pelo Nordeste, ainda em 1997, principalmente entre lideranças do setor público. Entretanto, um dos elementos essenciais da política de clustering, que é a percepção pelos agentes privados de que a sua cooperação dentro de um espírito cívico para promover o bem comum ainda está evoluindo de forma muito tímida. As mudanças ideológicas, contudo, sempre são lentas, mesmo quando tendem a prevalecer. Nesse caso, elas deverão ser bem-sucedidas se os governos continuarem empenhados na implementação desta estratégia de desenvolvimento. A incorporação da estratégia de clustering como uma das principais políticas de desenvolvimento na Bahia e em Pernambuco terá um papel fundamental para isso. O governo do estado do Ceará já tem prática de construção de política de desenvolvimento muito semelhante ao que seria preconizado por uma política de clustering. Conseqüentemente, as mudanças na ideologia dominante causada por esta já estão em curso naquele estado há algum tempo.

\section{REFERÊNCIAS BIBLIOGRÁFICAS}

BALASSA, B. Development Strategies in Semi-Industrial Economies. Baltimore: John Hopkins University Press, 1982.

BARROS, A. "New Growth Theory and Economic Development." Journal of International Development, 5(5): 1993.

. “O Papel dos Salários Reais na Determinação da Renda: Um Teste Empírico para o Brasil com Dados para o Período 1971-86.” Revista Brasileira de Economia, 3(48): 325-353, 1994.

BASU, S., J. FERNALD, “Returns to Scale in U.S. Production: Estimates and Implications”. Journal of Political Economy, 105(2): 249-283, 1997.

HENTON, D., J. MELVILLE e K. WALESH Grassroots Leaders for a New Economy: How Civic Entrepreneurs are Building Prosperous Communities. San Francisco: Jossey-Bass, 1997.

KRUEGER, A. "The Political Economy of the Rent-Seeking Society." American Economic Review, (64):291-303, 1974. 1996.

. "Trade Policy and Economic Development: How We Learn.” American Economic Review,

LALL, S. “Technological Capabilities and Industrialization”. World Development, 20(2): 165-86, 1992.

. "The East Asian Miracle: Does the Bell Toll for Industrial Strategy?” Em H. Singer, N. Hatti e R. Tandon (orgs.), Export-Led Versus Balanced Growth in the 1990s. New World Order Series, B.R. Publishing Corporation, V. 13, p. 343-62, Delhi, 1998.

MADDISON, A. Dynamic Forces in Capitalist Development: a Long Run Comparative View. Oxford: Oxford University Press, 1991. 
PORTER, M. "Clusters and the New Economics of Competition". Harvard Business Review, (Novembro-Dezembro): 77-90, 1998a.

On Competition. Princeton: Princeton University Press, 1998b.

PUTTMAN, R., LEONARDI, R. e NANETTI, R.. Making Democracy Work: Civic Traditions in Modern Italy. Princeton: Princeton University Press, 1992.

PNUD. Relatório Anual do Desenvolvimento Econômico 1997. Oxford: Oxford University Press, 1997.

RICARDO, D. Principles of Political Economy and Taxation. Cambridge: Cambridge University Press, 1871.

ROMER, P. “The Origins of Endogenous Growth.” Journal of Economic Perspectives, (8)1: 3-22, 1994.

SCHMITZ, H. "Small Shoemakers and Fordist Giants: Tale of a Supercluster." World Development, (23)1: 9-28, 1995.

SHLEIFER, A. “Externalidades como Motor do Crescimento.” Em F. H. Barbosa (org.), Estabilização e Crescimento na América Latina, Rio de Janeiro: Livros Técnicos e Científicos, 1991.

STIGLITZ, J. “Alternative Tactics and Strategies for Economic Development.” Em A. Dutt e K. Jameson (orgs.), New Direction in Development Economics. Hants: Edward Elgar, 1992. 